Portland State University

PDXScholar

$1-2022$

\title{
Evaluation of Posted Speed Limits Reductions on Urban Roads with a High Percentage of Cyclists
}

Jaclyn S. Schaefer

Portland State University, jsschae@pdx.edu

Miguel Figliozzi

Portland State University, figliozzi@pdx.edu

Avinash Unnikrishnan

Portland State University, uavinash@pdx.edu

Follow this and additional works at: https://pdxscholar.library.pdx.edu/cengin_fac

Part of the Civil and Environmental Engineering Commons

Let us know how access to this document benefits you.

\section{Citation Details}

To be published as: Schaefer, J. S., Figliozzi, M. A., \& Unnikrishnan, A. (2022). Evaluation of Posted Speed Limits Reductions on Urban Roads with a High Percentage of Cyclists, Forthcoming Transportation Research Record.

This Pre-Print is brought to you for free and open access. It has been accepted for inclusion in Civil and Environmental Engineering Faculty Publications and Presentations by an authorized administrator of PDXScholar. Please contact us if we can make this document more accessible: pdxscholar@pdx.edu. 


\title{
Evaluation of Posted Speed Limits Reductions on Urban Roads with a High Percentage of Cyclists
}

\author{
Jaclyn S. Schaefer \\ Research Associate \\ Transportation Technology and People (TTP) Lab \\ Department of Civil and Environmental Engineering \\ Portland State University, Portland, Oregon, 97201 \\ Email: jsschae@pdx.edu \\ Miguel A. Figliozzi (corresponding author) \\ Professor \\ Transportation Technology and People (TTP) Lab \\ Department of Civil and Environmental Engineering \\ Portland State University, Portland, Oregon, 97201 \\ Email: figliozzi@pdx.edu \\ Avinash Unnikrishnan \\ Professor \\ Transportation Technology and People (TTP) Lab \\ Department of Civil and Environmental Engineering \\ Portland State University, Portland, Oregon, 97201 \\ Email: uavinash@pdx.edu
}

Submitted July 21, 2021

Revised November 27, 2021

Accepted for publication January 5, 2022

\section{Journal Reference}

Schaefer, J. S., Figliozzi, M. A., \& Unnikrishnan, A. (2022). Evaluation of Posted Speed Limits Reductions on Urban Roads with a High Percentage of Cyclists, Forthcoming Transportation Research Record. 


\begin{abstract}
This paper presents a before and after analysis of the impact of posted speed limit (PSL) changes on passenger car (FHWA class two vehicles) speeds in Portland, OR. The study focuses on urban roads, comparing sites that underwent a PSL 5-mph reduction (treatment sites) and sites where the PSL did not change (control sites). Sites with a high percentage of and priority for cyclists (neighborhood greenways) and sites with a more standard traffic composition were compared. Differences in speed characteristics such as mean and $85^{\text {th }}$ percentile speeds, the speed variance, and the proportion of vehicles exceeding a speed threshold (relative to the posted speed limit) were evaluated on aggregate and individual scales. A series of statistical hypothesis tests were employed to assess changes in the speed characteristics among individual dataset pairs. The results suggest distinct differences between the treatment and control groups and neighborhood greenway and non-greenway sites. Although there is a high degree of variability, the treatment group experienced more decreases in the speed characteristics, and by a greater amount than the control group, on average. Within the treatment group, sites with a priority for cyclists were even more likely to experience a larger reduction in operating speeds. These results could be interpreted as link level data providing indirect yet supporting evidence for the safety in numbers hypothesis and changes in motorists' behavior on neighborhood greenways.
\end{abstract}

Keywords: Operating speed, bicycles, passenger car, hypothesis testing, urban roads, speed limit, safety in numbers 


\section{INTRODUCTION}

Speed limits throughout the U.S. are typically set by state legislation and determined based on the roadway functional class and geographic area. Traditionally, in zones where these statutory limits are deemed inappropriate due to specific traffic, roadway, or safety factors, speed limits are established by conducting an engineering study.

In the U.S., traditional guidance from the Manual on Uniform Traffic Control Devices (MUTCD) (1) states that when an engineering study is conducted, the speed limit should be set within $5 \mathrm{mph}$ of the $85^{\text {th }}$ percentile speed of free-flowing traffic (note that new versions of the MUTCD are likely to incorporate a different type of guidance or language). The belief supporting the utilization of the $85^{\text {th }}$ percentile speed is that the majority of drivers naturally choose safe and reasonable speeds according to the given conditions and setting the limit near the speed at which $85 \%$ of drivers travel at or below improves compliance and reduces the burden of enforcement.

The $85^{\text {th }}$ percentile speed used to have wide acceptance and support as the basis for setting speed limits, particularly within the U.S., however, alternative methods such as the Safe System approach have been in practice in parts of Europe and Asia since the late 1990s (2). In more recent years, the assumption that drivers are aware of and select the safest speed for all users of the road has received a great level of scrutiny. It has also been argued that setting the posted speed limit (PSL) based on $85^{\text {th }}$ speed percentiles is likely to generate an upward drift in operating speeds over time (3). Additionally, the $85^{\text {th }}$ percentile speed methodology is heavily weighted toward motor vehicles and does not balance multimodal needs. As such, alternative speed zoning guidelines that are drastically different from the traditional method are being proposed within the U.S. For example, the proliferation of Vision Zero campaigns (a Safe System approach) has led many U.S. cities to act toward lowering speed limits, especially in urban and residential areas where there are high numbers of active travelers. On roadways with a high percentage of active users, a more balanced approach may result in fewer crashes and fatalities, as well as better driving, bicycling, and walking environments. However, excessively reducing speed limits on roadways without the appropriate roadway and traffic characteristics may negatively affect mobility and the overall level of safety.

Many previous studies have attempted to determine which contextual, geometric, or environmental factors may influence operating speeds $(4)(5)(6)(7)$, but few of them have included variables related to active travel or analyzed sites where active travel is prevalent. In addition, only a low number of these studies were concentrated on urban environments or with a high percentage of active travelers.

The focus of this research is to examine the effects of a 5-mph PSL reduction on urban roads with a high percentage of cyclists, i.e., when cyclists represent more than $15 \%$ of the roadway traffic, usually on shared-use roadways that are also designated as neighborhood greenways. Speed studies conducted at the same locations before and after a PSL reduction (treatment sites) were compared to repeat studies performed at locations where the PSL did not change (control sites). Performance measures evaluated included the mean and 85 th percentile speeds, the speed variance, and the proportion of vehicles exceeding a speed threshold (relative to the PSL). The findings from this study may help guide speed zoning decisions in urban areas with a high percentage of cyclists. 


\section{LITERATURE REVIEW}

Previous research has suggested several factors that may influence operating speeds. For example, factors such as the lane or road width, the number of lanes, and segment length have been positively associated with operating speeds (4)(5).

Negative associations have been observed between operating speed and access density or the density of roadside objects, such as trees and poles (4)(6)(7). Few studies have considered variables pertaining to active travel. Positive associations have been observed between operating speed and the presence of bicycle lanes or routes (5)(7), and a negative association between operating speed and the presence of pedestrian crossings has been observed (7).

One of the most important factors to influence operating speeds is the PSL. From a study of suburban arterial roads, Fitzpatrick et al. (6) indicated that the PSL was the only statistically significant variable out of several geometric and roadway variables examined, affecting operating speeds on straight segments. Himes et al. (8) also discovered the influence of the PSL, suggesting that it explains $82 \%$ of the variation in operating speed on urban and rural highways. In both studies, positive relationships between operating speed and the PSL were observed.

Despite the associations between speed and the PSL, a decrease in the PSL is not likely to produce an equivalent decrease in operating speeds. A meta-analysis on the relationship between changes in the PSL and changes in the mean traffic speed revealed a high degree of variability in outcomes. The research suggested that a $10 \mathrm{~km} / \mathrm{h}(6.2 \mathrm{mph})$ reduction in the PSL would likely produce a reduction in the mean traffic speed of $2.5 \mathrm{~km} / \mathrm{h}(1.6 \mathrm{mph})(9)$. Guidance on speed management policies has also advised that the average change in mean operating speed will be approximately one-quarter of the change in the speed limit when no other interventions have been performed (2).

The variability in speed outcomes relating to PSL reductions can be demonstrated with two studies. Islam et al. (10) found that mean speeds on urban residential roads were reduced nearly $4-5 \mathrm{~km} / \mathrm{h}(2.5-3 \mathrm{mph})$ three and six months after the PSL was decreased from $50 \mathrm{~km} / \mathrm{h}$ (31 $\mathrm{mph}$ ) to $40 \mathrm{~km} / \mathrm{h}(25 \mathrm{mph})$, while speeds at control sites showed an increasing trend. Conversely, $\mathrm{Hu} \&$ Cicchino (11) did not observe a significant difference in the mean or $85^{\text {th }}$ percentile speeds after the default PSL in Boston was lowered from $30 \mathrm{mph}$ to $25 \mathrm{mph}$. The proportions of vehicles exceeding speed thresholds of $25 \mathrm{mph}, 30 \mathrm{mph}$, and $35 \mathrm{mph}$ did decrease, however. The results of Islam et al. (10) and $\mathrm{Hu} \&$ Cicchino (11) indicate that speed reductions are contingent upon other factors in addition to the PSL. Enforcement expectations, marketing campaigns, and social norms may also influence a driver's choice of speed (12)(13) and it is necessary to control for such effects in studies such as those discussed previously to better isolate the roles of the studied factors.

Although the current MUTCD guidance is to set the PSL within $5 \mathrm{mph}$ of the $85^{\text {th }}$ percentile operating speed, adjustments are permitted for risk factors related to road geometry, the pace speed, roadside development, parking practices, pedestrian activity, and crash experience (1). There are no specific considerations for bicyclists or other active travelers (e.g., electric scooters), however.

Expert systems approaches to setting speed limits attempt to simplify the process by relying on data-driven approaches and decision rules to produce consistent recommendations. Research by Fitzpatrick et al. (14) has recently created a speed limit-setting spreadsheet tool that helps users make informed decisions related to establishing speed limits. However, the tool does not offer specific guidance for roads with a high percentage of active travelers. 
The MUTCD and expert systems approaches are heavily weighted toward motorized vehicles, basing PSL recommendations on the observed speed of motorized traffic. While these approaches may be appropriate for higher functionally classed roadways or in rural environments, urban environments are much more complex due to increased opportunities for conflict and multimodal travel. New guidance from the Oregon Department of Transportation (ODOT) suggests that basing the PSL on the $50^{\text {th }}$ percentile speed is more appropriate in urban environments. Vulnerable users and the type of facilities available to them should be considered when making changes (15). Alternatively, under the Safe Systems approach, PSLs are determined by what is safest for all people using the road, and infrastructure is built to support that speed. The National Association of City Transportation Officials (NACTO) offers guidance for setting PSLs through the Safe Systems approach (16). However, the outcomes of these updated or alternative guidelines for setting PSLs have not been thoroughly studied or evaluated.

The literature also indicates that the percentage and number of cyclists on roadways have an impact on safety outcomes. This is commonly known as the "safety in numbers" effect which indicates the likelihood of an individual cyclist to be injured decreases as the number of cyclists increases (17). Traffic calming and reducing speed limits improves safety and increases walking and cycling volumes (18). In addition, lower motorized vehicle speeds increase cyclists' comfort (19). Hence, there is likely a positive feedback loop among increased cycling safety, higher cycling volumes, and lower motorized traffic speeds. A meta-analysis of cycling safety studies indicates there is clear evidence supporting the safety in numbers hypothesis for active travelers but also indicates that no study has controlled properly for all potential confounding factors (20).

The general lack of previous research on setting PSLs on urban roads with a high percentage of active travelers emphasizes the need for the current study. The current study assesses the outcomes of a 5-mph reduction in the PSL on operating speeds, with a focus on urban roads with high bicycle volumes.

\section{DATA}

Speed data were collected by the Portland Bureau of Transportation (PBOT) from 2011 to 2019 using pneumatic tubes configured to classify vehicles according to the FHWA Scheme F (21) and to record speed in 1-mph increments. Datasets were collected from 39 directional sites for a minimum of two survey periods. More than two surveys were performed at 11 of the sites. The data collection produced 95 unidirectional datasets. Using all possible combinations of the repeat survey datasets, 80 before-after pairs were produced for comparison. Changes to the PSL occurred between subsequent surveys in 43 of the pairs. These pairs are henceforth referred to as treatment pairs. No changes were made to the PSL between repeat surveys in the remaining 37 pairs, which are referred to as control pairs.

Treatment locations were selected so that they were not adjacent to each other and sharing the exact same roadway characteristics to avoid spatial correlations. Control locations were selected based on the proximity to treatment locations and similarity of roadway characteristics. Roadway characteristics considered included geometry and traffic control as well as proximity to stop signs or traffic signals, transit and pedestrian activity, parking and sidewalk presence and geometry, pedestrian crossings, topography, and land use. No specific traffic enforcement operations were noted for any location during the survey periods, but PBOT did begin a citywide speed safety education campaign in the spring of 2018 which included advertisements on billboards, buses, movie theaters, and social media channels. 
Table 1 summarizes the basic characteristics of the 43 treatment and 37 control dataset pairs. The PSL shown for the treatment pairs is the PSL during data collection of the subsequent, 'after' survey. For treatment pairs, the initial, 'before' PSL was posted 5-mph higher than during the 'after' survey at all sites.

TABLE 1 Summary of the basic characteristics of the dataset pairs.

\begin{tabular}{|l|r|r|}
\hline Functional Class & Treatment & Control \\
\hline Local & 20 & 10 \\
\hline Urban Collector & 16 & 24 \\
\hline Minor Arterial & 1 & 0 \\
\hline Principal Arterial & 6 & 3 \\
\hline Bike Facilities & & \\
\hline Shared & 30 & 24 \\
\hline No Facility & 4 & 10 \\
\hline Bike Lane* & 9 & 3 \\
\hline PSL** & & \\
\hline 35 & 0 & 1 \\
\hline 30 & 7 & 2 \\
\hline 25 & 2 & 20 \\
\hline 20 & 34 & 14 \\
\hline
\end{tabular}

*Includes bike lanes with increased spatial separation from traffic (buffered).

**For treatment pairs, the PSL of the 'after' dataset is given

Table 1 shows that most of the dataset pairs analyzed were from locations along lowerclassed roadways (local and urban collector) with lower speed limits in the range of 20-25 mph. Two-thirds of the dataset pairs were from shared road facilities. All the shared road facilities studied within this research correspond to streets that are designated as neighborhood greenways. Neighborhood greenways are residential streets with low motorized traffic volumes and speeds where priority is given to active travelers such as cyclists. Accordingly, cyclists tend to comprise a higher share of the total traffic on these streets. These streets are posted at 20-25 mph and are classified as local or urban collectors, correlating to the abundance of dataset pairs in Table 1 sharing those basic characteristics. Neighborhood greenways have several other characteristics that differentiate them from non-greenway roads. Neighborhood greenways are identified by signage and the presence of sharrows (shared lane pavement markings), while continuous centerline markings are absent. Neighborhood greenways also feature a varying mix of traffic calming measures such as speed humps, circles, and diverters which are used to manage motorized traffic speed and volume (22). Traffic calming measures are generally implemented based on need, but all neighborhood greenways studied in this research featured at least one of these traffic calming measures. Examples of a neighborhood greenway and a non-greenway from this study are displayed in Figure 1.

Class two observations (passenger cars) were retained for analysis as they are the predominant motorized vehicle type. Histograms were constructed to inspect for normally distributed speeds. Differences between the mean and median speeds were also calculated to 
check for deviations from normal distributions. In all datasets, the differences between the mean and median speeds were less than $1 \mathrm{mph}$.

For each dataset, a preliminary exploration was conducted, whereby class two observations were aggregated into 15-minute intervals. The mean speed, mean gap time between vehicles, and the vehicle count were calculated for each 15-minute interval. Scatterplots of the mean gap time or vehicle count versus the mean speed were created to investigate relationships between these metrics. A distinct pattern difference was revealed between datasets from neighborhood greenways and those from non- greenways. Non-greenway datasets exhibited evidence of a positive relationship between mean speed and mean gap time or a negative relationship between mean speed and vehicle count. Conversely, these relationships were absent in almost all (97\%) of the neighborhood greenway datasets. More details on the relationship between mean speed and mean gap time can be found in (23).

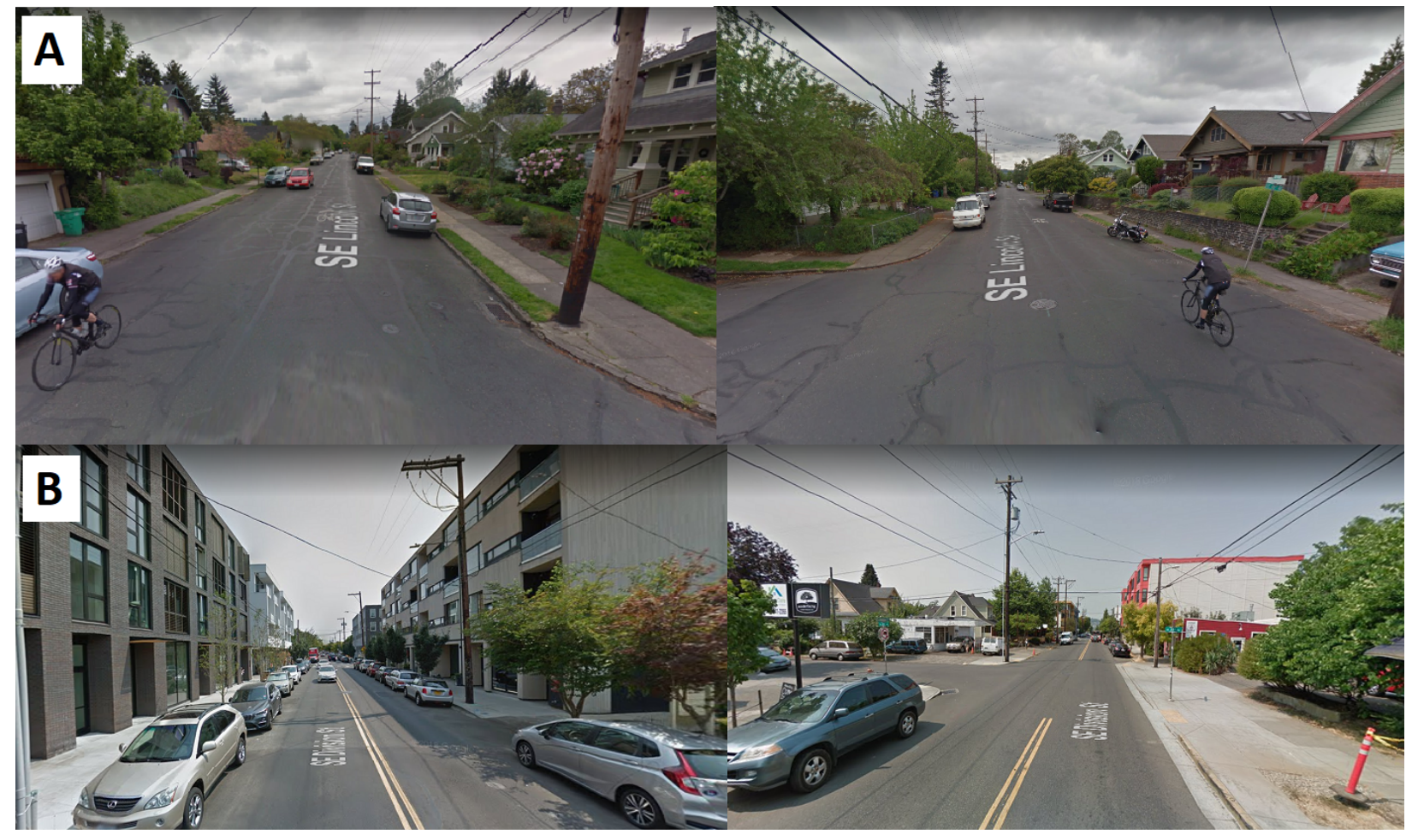

Figure 1 Example of a neighborhood greenway (A) and a non-greenway (B) Source: Google Street View 


\begin{abstract}
ANALYSIS METHODS
Differences in performance measures from before to after were evaluated between aggregated datasets and between individual dataset pairs. Multiple performance measures were selected and investigated to provide a broad overview of the operating speed behaviors in the datasets. The performance measures varied slightly between the aggregate and individual analyses and are discussed in the subsequent sections.
\end{abstract}

\title{
Aggregate Analysis
}

To calculate differences on the aggregate level, datasets were aggregated according to whether they were part of a treatment or control pair, the PSL at the time of the survey, and the neighborhood greenway designation. The decision to separate datasets by neighborhood greenway designation was guided by the results of the preliminary data exploration, suggesting there may be distinct differences in speed behavior between the two categories. Additionally, the neighborhood greenway designation was used as a proxy to distinguish sites with a high percentage of cyclists from sites with more typical percentages. Performance measures were computed for each aggregation, and differences were calculated as the after value minus the before value. Hence, a negative difference represents a decrease in the performance measure statistic, and a positive difference represents an increase in the performance measure statistic.

Performance measures examined included the mean and $85^{\text {th }}$ percentile speeds, the pace (i.e., the 10-mph range containing the most observations), the percent of vehicles within the pace, and the percent of vehicles exceeding three speed thresholds. The speed thresholds were defined as (i) the PSL of the after period, (ii) the PSL of the after period plus $5 \mathrm{mph}$, and (iii) the PSL of the after period plus $10 \mathrm{mph}$.

\section{Individual Analysis}

Differences in the mean and $85^{\text {th }}$ percentile speeds, the speed variance, and the proportion of vehicles exceeding the PSL of the after dataset were compared among individual dataset pairs using a series of hypothesis tests, described in the following sections. A 95\% confidence level was used for all hypothesis tests. For $p<0.05$, the null hypothesis is rejected, suggesting the alternative hypothesis is true. If $p \geq 0.05$, the sample data fail to reject the null. Note that for control pairs, the PSL of the after dataset is equal to the PSL of the before dataset. For all hypothesis tests henceforward, the subscripts B and A symbolize the before and after conditions, respectively.

\section{Mean Speed Hypothesis Tests}

The statistical significance of differences in mean speeds from the before condition to the after condition was assessed using Welch two-sample $t$-tests. Two hypotheses were tested for all dataset pairs in the treatment and control groups.

The first null hypothesis and its alternative were selected to indicate whether the mean speeds of the before and after conditions were equal $\left(\mathrm{H}_{0}: \mu_{\mathrm{B}}-\mu_{\mathrm{A}}=0\right)$ or if the mean speed of the after condition was greater than the before condition $\left(\mathrm{H}_{\mathrm{A}}: \mu_{\mathrm{B}}-\mu_{\mathrm{A}}<0\right)$. The second null hypothesis and its alternative were chosen to test if the mean speed in the after condition decreased by $1.25 \mathrm{mph}$ compared to the before condition $\left(\mathrm{H}_{0}: \mu_{\mathrm{B}}-\mu_{\mathrm{A}}=1.25\right)$, or if the mean speed decreased by more than $1.25 \mathrm{mph}$ from before to after $\left(\mathrm{H}_{\mathrm{A}}: \mu_{\mathrm{B}}-\mu_{\mathrm{A}}>1.25\right)$. The value of $1.25 \mathrm{mph}$ was chosen as the threshold for the second null hypothesis based on research by Elvik 
(9), which concluded that a 1:4 ratio of the change in mean operating speed to the change in the PSL could be expected for a 5-mph reduction in the PSL.

\section{5th Percentile Speed Hypothesis Tests}

The $85^{\text {th }}$ percentile operating speed has traditionally been used as an important input when setting speed limits in the U.S. Thus, the magnitude or direction of change in the $85^{\text {th }}$ percentile speed is of interest to this study. A modified $t$-test was used to determine the significance of differences in the $85^{\text {th }}$ percentile speeds from the before condition to the after condition. Details of the test can be found in Hou et al. (24).

Two null hypotheses were tested, constructed similarly to those for mean speeds. The first null hypothesis tested whether the $85^{\text {th }}$ percentile speeds were equal from before to after $\left(\mathrm{H}_{0}\right.$ : $\left.\zeta_{85, \mathrm{~B}}-\zeta_{85, \mathrm{~A}}=0\right)$, with the alternative $\left(\mathrm{H}_{\mathrm{A}}: \zeta_{85, \mathrm{~B}}-\zeta_{85, \mathrm{~A}}<0\right)$ suggesting the $85^{\text {th }}$ percentile speed was higher in the after period.

The second test was selected to indicate whether the $85^{\text {th }}$ percentile speed of the after condition was $1.25 \mathrm{mph}$ lower than the before condition $\left(\mathrm{H}_{0}: \zeta_{85, \mathrm{~B}}-\zeta_{85, \mathrm{~A}}=1.25\right)$, or if the $85^{\text {th }}$ percentile speed was reduced by more than $1.25 \mathrm{mph}$ from before to after $\left(\mathrm{H}_{\mathrm{A}}: \zeta_{85, \mathrm{~B}}-\zeta_{85, \mathrm{~A}}\right.$ $>1.25)$.

\section{Speed Variance Hypothesis Test}

The equivalence of speed variance between the before and after periods for all datasets was analyzed using a F-test, $\mathrm{H}_{0}:{\sigma_{\mathrm{B}}}^{2}=\sigma_{\mathrm{A}}{ }^{2}$. Here, a rejection of the null would suggest the speed variance either increased or decreased in the after period compared to before $\left(\mathrm{H}_{\mathrm{A}}: \sigma_{\mathrm{B}}{ }^{2} \neq \sigma_{\mathrm{A}}{ }^{2}\right)$.

\section{Proportion Exceeding Speed Threshold Hypothesis Test}

The proportions of vehicles exceeding a defined speed threshold were compared for all treatment and control pairs using a chi-square test. In the chi-square test, the null hypothesis states that the proportion of class two vehicles exceeding the speed threshold in the before dataset is equal to the proportion of class two vehicles exceeding the speed threshold in the after dataset, $\mathrm{H}_{0}$ : $\mathrm{P}_{\mathrm{B}}-$ $\mathrm{P}_{\mathrm{A}}=0$. Rejection of the null would indicate that the percent of vehicles traveling at speeds higher than the threshold either decreased or increased in the after period $\left(\mathrm{H}_{\mathrm{A}}: \mathrm{P}_{\mathrm{B}}-\mathrm{P}_{\mathrm{A}} \neq 0\right)$. For this hypothesis test, the PSL of the dataset from the after period was chosen as the speed threshold. Thus, for control pairs, the speed threshold is also equal to the PSL of the before dataset.

\section{RESULTS}

\section{Aggregated Datasets}

The results for the treatment datasets are provided in Table 2. Note that the number of before datasets may not necessarily be equal to the number of after datasets due to performing more than two surveys at some locations. Within the treatment datasets, the percentage of vehicles within the pace increased for each speed group. Neighborhood greenway sites showed consistent decreases in all other performance measure categories. In other words, on average, operating speeds and the percent of vehicles exceeding the speed thresholds were reduced in the after period. Similar trends of decreased speeds and percent of vehicles exceeding the speed thresholds were observed for most of the remaining, non-greenway treatment groups, although the low numbers of datasets within these groups do not allow for any broad conclusions to be drawn. 
TABLE 2 Performance measure averages for all datasets included in a treatment pair, grouped by PSL and greenway status.

\begin{tabular}{|c|c|c|c|c|c|c|c|c|}
\hline \multicolumn{4}{|c|}{ Non- Greenways } & \multirow[b]{2}{*}{$\begin{array}{l}\text { \% Exc. } \\
30 \mathrm{mph}\end{array}$} & \multirow[b]{2}{*}{$\begin{array}{l}\text { \% Exc. } \\
35 \text { mph }\end{array}$} & \multirow[b]{2}{*}{$\begin{array}{l}\text { \% Exc. } \\
40 \mathrm{mph}\end{array}$} & \multirow[b]{2}{*}{ Pace* } & \multirow[b]{2}{*}{$\begin{array}{l}\% \text { in } \\
\text { Pace }\end{array}$} \\
\hline & PSL & Mean & 85th & & & & & \\
\hline Before $(\mathrm{N}=4)$ & 35 & 34.37 & 39.25 & 80.39 & 44.30 & 10.76 & 30.25 & 71.34 \\
\hline After $(\mathrm{N}=5)$ & 30 & 33.15 & 37.40 & 75.01 & 29.15 & 5.51 & 28.80 & 75.99 \\
\hline Difference & & -1.22 & -1.85 & -5.38 & -15.15 & -5.25 & -1.45 & 4.65 \\
\hline Before $(\mathrm{N}=2)$ & 30 & 27.28 & 31.50 & 66.41 & 22.96 & 3.62 & 23.00 & 74.68 \\
\hline After $(\mathrm{N}=2)$ & 25 & 25.34 & 29.50 & 48.02 & 10.76 & 1.43 & 20.50 & 77.68 \\
\hline Difference & & -1.94 & -2.00 & -18.39 & -12.20 & -2.20 & -2.50 & 3.00 \\
\hline Before $(\mathrm{N}=4)$ & 25 & 20.26 & 25.25 & 47.78 & 14.25 & 2.05 & 15.50 & 70.35 \\
\hline After $(\mathrm{N}=2)$ & 20 & 20.26 & 24.50 & 48.06 & 11.98 & 1.91 & 15.50 & 73.60 \\
\hline Difference & & 0.00 & -0.75 & 0.29 & -2.28 & -0.14 & 0.00 & 3.25 \\
\hline \multicolumn{4}{|c|}{ Neighborhood Greenways } & & & & & \\
\hline Before $(\mathrm{N}=22)$ & 25 & 21.30 & 25.00 & 59.84 & 13.34 & 1.17 & 17.07 & 82.70 \\
\hline After $(\mathrm{N}=22)$ & 20 & 19.51 & 23.06 & 39.74 & 7.02 & 0.63 & 15.00 & 82.85 \\
\hline Difference & & -1.78 & -1.94 & -20.10 & -6.32 & -0.53 & -2.07 & 0.15 \\
\hline
\end{tabular}

$\mathrm{N}=$ the number of datasets averaged

*Lower limit of the 10-mph range

Table 3 shows the results of the aggregated dataset analysis for the control groups. Small to negligible changes within the performance measures were observed for the control groups. There does not appear to be a trend in either direction for the changes observed. In general, the magnitude of differences from before to after was larger in the treatment groups than the control groups, particularly when considering the percentages exceeding the speed thresholds. 
TABLE 3 Performance measure averages for all datasets included in a control pair, grouped by PSL and greenway status.

\begin{tabular}{|c|c|c|c|c|c|c|c|c|}
\hline \multicolumn{4}{|c|}{ Non- Greenways } & \multirow[b]{2}{*}{$\begin{array}{c}\text { \% Exc. } 35 \\
\text { mph }\end{array}$} & \multirow[b]{2}{*}{$\begin{array}{c}\text { \% Exc. } 40 \\
\text { mph }\end{array}$} & \multirow[b]{2}{*}{$\begin{array}{c}\text { \% Exc. } 45 \\
\text { mph }\end{array}$} & \multirow[b]{2}{*}{ Pace* } & \multirow[b]{2}{*}{$\%$ in Pace } \\
\hline & PSL & Mean & 85th & & & & & \\
\hline Before $(\mathrm{N}=1)$ & 35 & 35.29 & 41.00 & 49.36 & 15.05 & 2.94 & 31.00 & 69.21 \\
\hline After $(\mathrm{N}=1)$ & 35 & 35.18 & 40.00 & 48.47 & 14.10 & 2.49 & 31.00 & 69.07 \\
\hline Difference & & -0.11 & -1.00 & -0.89 & -0.95 & -0.45 & 0.00 & -0.14 \\
\hline Before $(\mathrm{N}=2)$ & 30 & 32.76 & 37.50 & 71.60 & 26.94 & 5.65 & 28.50 & 73.18 \\
\hline After $(\mathrm{N}=2)$ & 30 & 32.88 & 37.00 & 72.59 & 25.95 & 5.00 & 28.50 & 76.05 \\
\hline Difference & & 0.12 & -0.50 & 0.99 & -0.98 & -0.66 & 0.00 & 2.87 \\
\hline Before $(\mathrm{N}=4)$ & 25 & 19.69 & 25.00 & 11.90 & 1.71 & 0.14 & 15.25 & 68.66 \\
\hline After $(\mathrm{N}=4)$ & 25 & 19.28 & 24.25 & 10.45 & 1.44 & 0.16 & 14.50 & 70.08 \\
\hline Difference & & -0.41 & -0.75 & -1.45 & -0.27 & 0.02 & -0.75 & 1.42 \\
\hline Before $(\mathrm{N}=5)$ & 20 & 21.40 & 25.80 & 58.74 & 18.34 & 3.26 & 16.80 & 72.63 \\
\hline After $(\mathrm{N}=5)$ & 20 & 20.95 & 25.40 & 55.20 & 15.41 & 2.22 & 16.60 & 74.13 \\
\hline Difference & & -0.45 & -0.40 & -3.54 & -2.93 & -1.04 & -0.20 & 1.50 \\
\hline \multicolumn{4}{|c|}{ Neighborhood Greenways } & & & & & \\
\hline Before $(\mathrm{N}=14)$ & 25 & 20.23 & 23.93 & 7.74 & 0.47 & 0.04 & 15.93 & 83.41 \\
\hline After $(\mathrm{N}=14)$ & 25 & 20.28 & 23.71 & 7.25 & 0.43 & 0.02 & 16.00 & 83.45 \\
\hline Difference & & 0.05 & -0.21 & -0.48 & -0.04 & -0.02 & 0.07 & 0.04 \\
\hline Before $(\mathrm{N}=7)$ & 20 & 19.69 & 23.49 & 40.86 & 7.77 & 0.74 & 15.07 & 81.67 \\
\hline $\operatorname{After}(\mathrm{N}=7)$ & 20 & 19.38 & 22.91 & 38.17 & 6.80 & 0.73 & 15.07 & 81.05 \\
\hline Difference & & -0.31 & -0.57 & -2.69 & -0.97 & -0.01 & 0.00 & -0.62 \\
\hline
\end{tabular}

$\mathrm{N}=$ the number of datasets averaged

*Lower limit of the 10-mph range 


\section{Individual Datasets}

A summary of the hypothesis testing results is displayed in Table 4. The table shows the percent of datasets that rejected the null hypothesis for each test. The results are categorized according to the treatment or control groups, as well as by the neighborhood greenway designations to facilitate comparisons.

TABLE 4 Percent of treatment and control dataset pairs producing statistically significant results for all hypothesis tests.

\begin{tabular}{|c|c|c|c|c|c|c|}
\hline \multirow{2}{*}{ Hypothesis Test } & \multicolumn{2}{|c|}{$\begin{array}{l}\text { Neighborhood } \\
\text { Greenway }\end{array}$} & \multicolumn{2}{|c|}{ Non- Greenway } & \multicolumn{2}{|c|}{ Combined } \\
\hline & Cont. & Treat. & Cont. & Treat. & Cont. & Treat. \\
\hline $\begin{array}{l}\mathbf{H}_{0}: \mu_{B}-\mu_{A}=0 \\
H_{A}: \mu_{B}-\mu_{A}<0\end{array}$ & 37.5 & 0.0 & 15.4 & 30.8 & 29.7 & 9.3 \\
\hline $\begin{array}{l}H_{0}: \mu_{B}-\mu_{A}=1.25 \\
H_{A}: \mu_{B}-\mu_{A}>1.25\end{array}$ & 8.3 & 73.3 & 7.7 & 38.5 & 8.1 & 62.8 \\
\hline $\begin{array}{l}\mathrm{H}_{0}: \zeta_{85, \mathrm{~B}}-\zeta_{85, \mathrm{~A}}=\mathbf{0} \\
\mathrm{H}_{\mathrm{A}}: \zeta_{85, \mathrm{~B}}-\zeta_{85, \mathrm{~A}}<0\end{array}$ & 12.5 & 0.0 & 7.7 & 7.7 & 10.8 & 2.3 \\
\hline $\begin{array}{l}H_{0}: \zeta_{85, \mathrm{~B}}-\zeta_{85, \mathrm{~A}}=1.25 \\
\mathrm{H}_{\mathrm{A}}: \zeta_{85, \mathrm{~B}}-\zeta_{85, \mathrm{~A}}>1.25\end{array}$ & 12.5 & 73.3 & 15.4 & 38.5 & 13.5 & 62.8 \\
\hline $\begin{array}{l}H_{0}: \sigma_{B}^{2}=\sigma_{A}^{2} \\
H_{A}: \sigma_{B}^{2}>\sigma_{A}^{2}\end{array}$ & 25.0 & 36.7 & 46.2 & 69.2 & 32.4 & 46.5 \\
\hline $\begin{array}{l}H_{0}: \sigma_{B}^{2}=\sigma_{A}^{2} \\
H_{A}: \sigma_{B}^{2}<\sigma_{A}^{2}\end{array}$ & 33.3 & 20.0 & 7.7 & 7.7 & 24.3 & 16.3 \\
\hline $\begin{array}{l}\mathbf{H}_{0}: \mathbf{P}_{B}-\mathbf{P}_{A}=0 \\
\mathbf{H}_{A}: \mathbf{P}_{B}-\mathbf{P}_{A}>0\end{array}$ & 29.2 & 100.0 & 38.5 & 61.5 & 32.4 & 88.4 \\
\hline $\begin{array}{l}\mathbf{H}_{0}: \mathbf{P}_{B}-\mathbf{P}_{A}=0 \\
\mathbf{H}_{A}: \mathbf{P}_{B}-\mathbf{P}_{A}<0\end{array}$ & 20.8 & 0.0 & 15.4 & 15.4 & 18.9 & 4.7 \\
\hline
\end{tabular}

Cont. $=$ control; Treat. $=$ treatment 


\section{Mean Speeds}

The first null hypothesis tested, stating the means of the before and after periods are equal, produced significant results $(p<0.05)$ for four out of the 43 treatment pairs tested $(9.3 \%)$. The results indicate that mean speeds increased in the after period, despite a decrease in the PSL. Increases in mean speeds ranged from $0.3 \mathrm{mph}$ to $1.4 \mathrm{mph}$. All four results rejecting the null occurred at sites that are not designated as neighborhood greenways. Bike lanes were present in two of the datasets. No bicycle facilities were present in the other two datasets.

In the control group, there were 11 pairs out of 37 tested (29.7\%) that rejected the null hypothesis. Increases ranged from $0.2 \mathrm{mph}$ to $2.3 \mathrm{mph}$. Nine of the 11 significant results were from locations carrying a neighborhood greenway designation.

Testing of the second null hypothesis, stating the mean speed of the before condition is $1.25 \mathrm{mph}$ greater than the mean speed of the after condition, yielded significant results for 27 of the 43 treatment pairs $(62.8 \%$ ), of which 22 were collected from designated neighborhood greenways. Decreases in mean speed up to approximately four and five miles per hour were observed at a few locations.

In comparison to the large number of significant results in the treatment group, only three out of 37 pairs from the control group (8.1\%) were observed to reject the second null hypothesis, suggesting that mean speeds did not decrease by more than $1.25 \mathrm{mph}$ at most sites.

The differences in mean speeds for all datasets, regardless of hypothesis test outcomes, can be visualized by the histograms in Figure 2, showing the treatment datasets on the left, and the control datasets on the right. From these histograms, it is clear that mean speeds in the treatment group were more likely to decrease and by a greater magnitude than those of the control group.
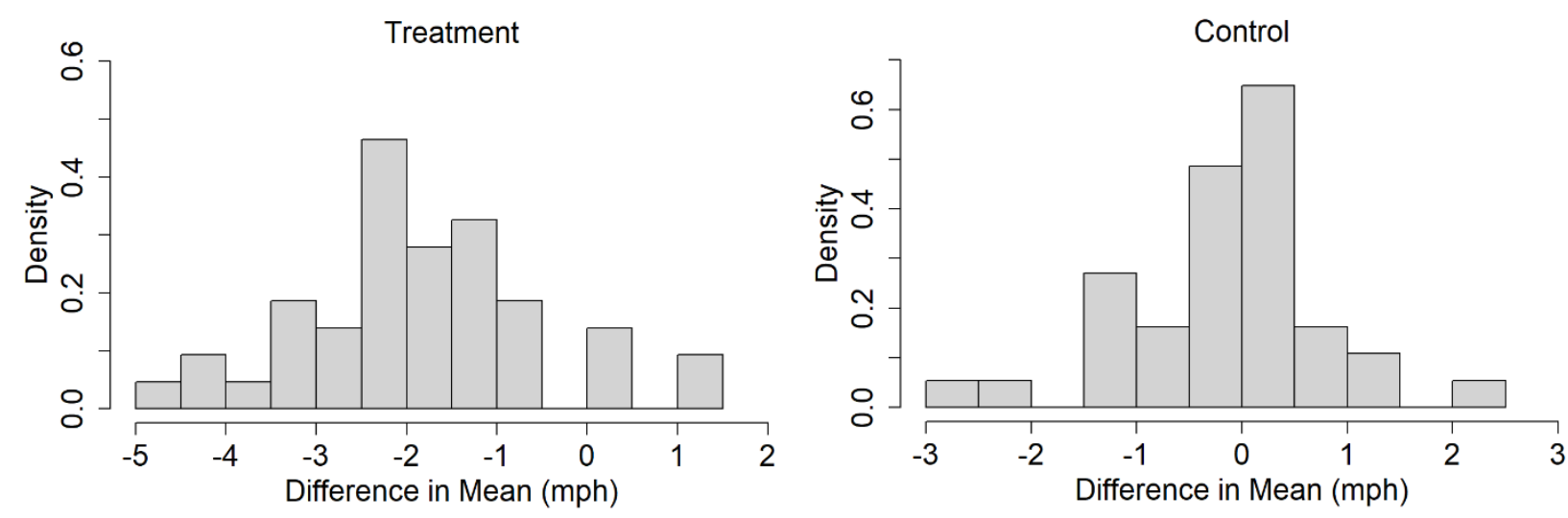

Figure 2 Histograms depicting the change in mean speeds from before to after for all treatment pairs (left) and all control pairs (right).

\section{$85^{\text {th }}$ Percentile Speeds}

Only one of the 43 treatment pairs $(2.3 \%)$ showed a statistically significant increase in the $85^{\text {th }}$ percentile speed, rejecting the null hypothesis that the before and after $85^{\text {th }}$ percentile speeds were equal. This dataset pair also showed a statistically significant increase in mean speed. The 
$85^{\text {th }}$ percentile speeds for this dataset pair were $37 \mathrm{mph}$ and $38 \mathrm{mph}$ for the before and after periods, respectively.

Four of the 37 control pairs (10.8\%) yielded significant results for the first null hypothesis for the $85^{\text {th }}$ percentile speeds $\left(\mathrm{H}_{0}: \zeta_{85, \mathrm{~B}}-\zeta_{85, \mathrm{~A}}=0\right)$; three of which are designated neighborhood greenways. All four of these control pairs also showed statistically significant increases in the mean speed. Increases in $85^{\text {th }}$ percentile speeds of one to three miles per hour were observed.

In the second hypothesis test for $85^{\text {th }}$ percentile speeds, 27 of the 43 treatment pairs $(62.8 \%)$ generated statistically significant results. These results indicate that the $85^{\text {th }}$ percentile speeds in the after condition were reduced by more than $1.25 \mathrm{mph}$. Most (22 out of 27) of the treatment pairs that rejected the null were collected from designated neighborhood greenways. Nearly all significant treatment pairs (25 of 27) also had statistically significant decreases in mean speed. Statistically significant decreases in $85^{\text {th }}$ percentile speeds for treatment pairs ranged from two to five miles per hour.

Only five of the 37 control pairs (13.5\%) rejected the second null hypothesis for $85^{\text {th }}$ percentile speeds. These decreases in $85^{\text {th }}$ percentile speeds were observed to range from two to three miles per hour.

\section{Speed Variance}

Of the 43 treatment pairs, 20 (46.5\%), were found to have a speed variance in the after period that was significantly lower than in the before period. Nine of these 20 treatment pairs were collected from non- greenways. Statistically significant increases in the speed variance between the before and after periods were observed in seven of the 43 treatment pairs $(16.3 \%)$.

Twelve of the 37 control pairs (32.4\%) rejected the null hypothesis in favor of a decrease in the variance during the after period. Conversely, the variance significantly increased from the before to after periods in nine of 37 control dataset pairs $(24.3 \%)$.

\section{Proportions Exceeding Speed Thresholds}

For treatment pairs, the proportion of vehicles exceeding the speed threshold decreased significantly $(p<0.05)$ in 38 of the $43(88.4 \%)$ pairs. Decreases ranged from $4 \%$ to 58\%, with an average decrease of $23 \%$. In comparison, only 12 of the 37 control datasets $(32.4 \%)$ rejected the null, with decreases in the proportions exceeding the speed threshold of $2 \%$ to $12 \%$.

Significant increases in the proportion of vehicles exceeding the speed threshold were found in two of the 43 treatment pairs (4.7\%), both of which were collected from sites with higher PSLs. Increases ranged from $7 \%$ to $9 \%$. For control pairs, significant increases of $1 \%$ to $8 \%$ were found in seven of the 37 dataset pairs $(18.9 \%)$.

\section{DISCUSSION}

Overall, the results of the data analyses suggest there are distinct differences in the outcomes of a 5-mph PSL reduction between treatment pairs and control pairs, and between neighborhood greenway sites and non-greenway sites. When comparing congested and all-day periods the overall results did not change (23).

The results of the before and after analysis indicate that treatment sites experience larger decreases in mean speeds than control sites - on the order of $1.5 \mathrm{mph}$ to $2 \mathrm{mph}$ on average for all 43 treatment pairs, compared to small or negligible changes in the 37 control pairs. Treatment sites also appear to have larger decreases in the 10-mph pace and larger increases in the percent 
of vehicles within the pace than control sites. This finding suggests that the operating speed reductions seen with the treatment datasets are more likely to be a result of the reduced PSLs rather than of chance or other global factors, such as the evolution of driver attitudes toward speed or compliance with the PSL.

The results of the hypothesis tests for mean speed are generally in agreement with those for the $85^{\text {th }}$ percentile speed across the treatment and control pairs. Nearly $63 \%$ of the 43 treatment pairs showed statistically significant reductions of more than $1.25 \mathrm{mph}$ in mean and $85^{\text {th }}$ percentile speeds, compared to only $8.1 \%$ and $13.5 \%$ of the 37 pairs in the control group for mean and $85^{\text {th }}$ percentile speeds, respectively. Furthermore, the percent of dataset pairs exhibiting any increase in mean or $85^{\text {th }}$ percentile speeds was lower for the treatment group than the control group.

Speed variance was significantly reduced in almost 50\% more treatment pairs than control pairs (47\% versus $32 \%$ ). Over half of these treatment pairs also experienced reduced mean speeds, but three treatment pairs indicated that mean speeds increased in the 'after' period. The distribution of significant decreases in speed variance was split fairly evenly between the neighborhood greenways and non- greenways for both the treatment and control groups. Meanwhile, increases in speed variance were proportionally more prevalent in control pairs than treatment pairs at neighborhood greenway locations.

The proportion of vehicles exceeding the speed threshold decreased in 2.7 times more treatment pairs than control pairs (88\% versus 32\%). Decreases in the proportion of vehicles exceeding the speed thresholds were also of smaller magnitude for control pairs than treatment pairs. As with speed variance, increases in the proportion of vehicles exceeding the speed threshold were more commonly observed in control pairs than treatment pairs.

Statistically significant reductions in all performance measure categories were more prevalent at the neighborhood greenway sites than non-greenway sites for the treatment group. For hypothesis testing of performance measure increases, non- greenways showed a higher propensity to produce statistically significant results than neighborhood greenways in the treatment group. It is clear that the speed behaviors and outcomes of a 5-mph PSL reduction on these two types of roads are quite different. Differences in traffic composition and the distinctive features of the neighborhood greenways may contribute to better outcomes of PSL reductions. In addition, traffic diversion or general changes related to mode choice or origin-destination matrices may be taking place on these neighborhood greenways after the PSLs are reduced. Despite small increases in VMT figures in the region during the data collection period, a trend towards a reduction in motorized volumes was observed on neighborhood greenways. In contrast, non- greenways experienced small increases in volumes on average. A high degree of variability was observed across sites, however. On some roadways, it is likely that changes in motorized volumes are also linked to reductions in speed characteristics such as the mean or $85^{\text {th }}$ percentile.

There is evidence that motorists' behavior is influenced by the number of cyclists, i.e., when cyclists are a minority then they may not be perceived or treated by motorists as road users with the same rights that motorists enjoy (25). Since neighborhood greenways are residential streets with low motorized traffic volumes and a high number of active travelers, cyclists tend to comprise a higher share of the total traffic on these streets and they are likely not perceived or treated as a minority by motorists. It is then likely that neighborhood greenway design and driver behavior contribute to higher reduction of operating speeds when PSL are reduced. Future 
research could measure additional benefits of PSL reductions on cyclists stress levels (26) and in particular for cyclists that tend to travel at slower speeds (27).

\section{CONCLUSIONS}

This research has presented a before and after analysis of passenger car speeds on urban roads that underwent a 5-mph reduction in the PSL (treatment sites) and roads where the PSL did not change (control sites). Within the treatment and control groups, sites that prioritize active travel and typically have high bicycle volumes were compared to sites with a more standard traffic function and composition. The change in the mean and $85^{\text {th }}$ percentile speeds, the speed variance, and the proportion of vehicles exceeding a speed threshold were evaluated in aggregate and individually through a series of hypothesis tests.

Overall, the results of the aggregate and individual dataset analyses suggest that PSL reductions of $5 \mathrm{mph}$ are likely to reduce speed characteristics such as mean or $85^{\text {th }}$ percentile by $1.25 \mathrm{mph}$. However, it is important to highlight that there is a high degree of variability in the outcomes and that a priori, it is not possible to ascertain whether a reduction in the PSL will reduce speed characteristics. For example, nearly $31 \%$ of the non-greenway treatment pairs experienced an increase in mean speed, even though the PSL was reduced by $5 \mathrm{mph}$. Additionally, approximately $16 \%$ of all treatment pairs experienced an increase in speed variance. Hence, it is always recommended to monitor speed characteristics before and after PSL changes and take additional measures to address situations where speed characteristics such as mean, $85^{\text {th }}$ percentile, and speed variance increase after a PSL reduction.

The statistical tests indicate that a PSL reduction is more likely to reduce speed characteristics on neighborhood greenways than on non- greenways. The presence of traffic calming features and shared roadway markings (sharrows) may contribute to the more successful outcomes of PSL reductions on these roads. It is also possible that traffic is diverting to nearby roads, and the speed reductions are linked to these changes in motorized volumes.

The results show more substantial operating speed reductions due to PSL reductions on roadways that prioritize active travel and typically have higher bicycle volumes. This has practical implications for cities fostering active transportation modes. The development of active transportation corridors that attract a higher number of cyclists are likely to see a positive change in motorists' behavior and a reduction in motorists operating speeds when PSL are reduced which in turn is likely to increase safety and attract more cyclists, thus creating a positive feedback loop. These findings can also be interpreted as indirect evidence supporting the safety in numbers hypothesis in relation to operating speeds and PSL changes.

Crash data analysis was not possible due to limited data availability regarding the number of crashes and years of data before and after PSL changes. Future research efforts should analyze the impact of PSL changes on crashes and other safety outcomes for cyclists, pedestrians, and motorized vehicles.

\section{ACKNOWLEDGMENTS}

This research was funded by an Oregon DOT SPR research project. We would like to acknowledge the guidance and support from the ODOT Research Section, especially to Xiugang (Joe) Li, who managed this research project, and the TAC members. The authors would also like to acknowledge Scott Batson and Tom Jensen of PBOT for providing the data used in this analysis. 


\section{AUTHOR CONTRIBUTIONS}

The authors confirm contribution to the paper as follows: study conception and design: MAF, AU; data collection: PBOT; analysis and interpretation of results: JSS, MAF, AU; draft manuscript preparation: JSS, MAF, AU. All authors reviewed the results and approved the final version of the manuscript. 


\section{REFERENCES}

1. US Department of Transportation. Manual on Uniform Traffic Control Devices; for Streets and Highways. US Department of Transportation, Federal Highway Administration; 2009.

2. OECD, European Conference of Ministers of Transport, OECD/ECMT Transport Research Centre. Speed management. OECD Publishing; 2006.

3. Gerald J, Teresa G, Hugh M, Raghavan S. Methods and practices for setting speed limits.[report. no. FHWA-SA-12-004]. USA Fed Highw Adm. 2012;

4. Dinh DD, Kubota H. Profile-speed data-based models to estimate operating speeds for urban residential streets with a $30 \mathrm{~km} / \mathrm{h}$ speed limit. IATSS Res. 2013 Mar;36(2):115-22.

5. Eluru N, Chakour V, Chamberlain M, Miranda-Moreno LF. Modeling vehicle operating speed on urban roads in Montreal: A panel mixed ordered probit fractional split model. Accid Anal Prev. 2013 Oct;59:125-34.

6. Fitzpatrick K, Carlson P, Brewer M, Wooldridge M. Design Factors That Affect Driver Speed on Suburban Streets. Transp Res Rec J Transp Res Board. 2001 Jan;1751(1):18-25.

7. Thiessen A, El-Basyouny K, Gargoum S. Operating Speed Models for Tangent Segments on Urban Roads. Transp Res Rec J Transp Res Board. 2017 Jan;2618(1):91-9.

8. Himes SC, Donnell ET, Porter RJ. Posted speed limit: To include or not to include in operating speed models. Transp Res Part Policy Pract. 2013 Jun;52:23-33.

9. Elvik R. Speed Limits, Enforcement, and Health Consequences. Annu Rev Public Health. 2012 Apr 21;33(1):225-38.

10. Islam MdT, El-Basyouny K, Ibrahim SE. The impact of lowered residential speed limits on vehicle speed behavior. Saf Sci. 2014 Feb;62:483-94.

11. $\mathrm{Hu} \mathrm{W}$, Cicchino JB. Lowering the speed limit from $30 \mathrm{mph}$ to $25 \mathrm{mph}$ in Boston: effects on vehicle speeds. Inj Prev. 2020 Apr;26(2):99-102.

12. Mannering F. An empirical analysis of driver perceptions of the relationship between speed limits and safety. Transp Res Part F Traffic Psychol Behav. 2009 Mar;12(2):99-106.

13. Toy S, Tapp A, Musselwhite C, Davis A. Can social marketing make 20mph the new norm? J Transp Health. 2014 Sep;1(3):165-73.

14. Fitzpatrick K, Das S, Pratt MP, Dixon K, Gates T. Development of a Posted Speed Limit Setting Procedure and Tool. 2021.

15. ODOT. Speed Zone Manual [Internet]. Oregon DOT, Speed Zone Manual. 2020 [cited 2020 Mar 18]. Available from: https://www.oregon.gov/odot/Engineering/Docs_TrafficEng/Speed-ZoneManual.pdf

16. NACTO. City Limits [Internet]. National Association of City Transportation Officials. 2021 [cited 2021 Nov 18]. Available from: https://nacto.org/safespeeds/ 
17. Jacobsen PL. Safety in numbers: more walkers and bicyclists, safer walking and bicycling. Inj Prev. 2003;9(4):205-9.

18. Pucher J, Buehler R. Cycling for Everyone: Lessons from Europe. Transp Res Rec J Transp Res Board. 2008 Jan;2074(1):58-65.

19. Blanc B, Figliozzi M. Modeling the Impacts of Facility Type, Trip Characteristics, and Trip Stressors on Cyclists' Comfort Levels Utilizing Crowdsourced Data. Transp Res Rec J Transp Res Board. 2016 Jan;2587(1):100-8.

20. Elvik R, Bjørnskau T. Safety-in-numbers: A systematic review and meta-analysis of evidence. Saf Sci. 2017 Feb;92:274-82.

21. Federal Highway Administration. Traffic monitoring guide. US Department of Transportation Washington, DC; 2016.

22. PBOT. What are Neighborhood Greenways? [Internet]. Portland.gov. 2021 [cited 2021 Nov 18]. Available from: https://www.portland.gov/transportation/what-are-neighborhood-greenways

23. Figliozzi M, Unnikrishnan A, Schaefer J. Update to Methodology for Setting Speed Limits in Urban Areas [Internet]. 2021. Report No.: Oregon DOT, SPR 827. Available from:

https://pdxscholar.library.pdx.edu/cengin_fac/560/

24. Hou Y, Sun C, Edara P. Statistical Test for 85th and 15th Percentile Speeds with Asymptotic Distribution of Sample Quantiles. Transp Res Rec J Transp Res Board. 2012 Jan;2279(1):47-53.

25. Prati G, Marín Puchades V, Pietrantoni L. Cyclists as a minority group? Transp Res Part F Traffic Psychol Behav. 2017 May;47:34-41.

26. Caviedes A, Figliozzi M. Modeling the impact of traffic conditions and bicycle facilities on cyclists' on-road stress levels. Transportation research part F: traffic psychology and behaviour. 2018 Oct 1;58:488-99.

27. Figliozzi M, Wheeler N, Monsere CM. Methodology for estimating bicyclist acceleration and speed distributions at intersections. Transportation research record. 2013 Jan;2387(1):66-75 